\title{
Mapping and Identification of the Urine Proteome of Prostate Cancer Patients by 2D PAGE/MS
}

\author{
Sanja Kiprijanovska, ${ }^{1}$ Sotir Stavridis, ${ }^{2}$ Oliver Stankov, ${ }^{2}$ Selim Komina, ${ }^{3}$ \\ Gordana Petrusevska, ${ }^{3}$ Momir Polenakovic, ${ }^{1}$ and Katarina Davalieva ${ }^{1}$ \\ ${ }^{1}$ Research Centre for Genetic Engineering and Biotechnology "Georgi D Efremov", Macedonian Academy of Sciences \\ and Arts, Krste Misirkov 2, 1000 Skopje, Macedonia \\ ${ }^{2}$ University Clinic for Urology, University Clinical Centre "Mother Theresa", 1000 Skopje, Macedonia \\ ${ }^{3}$ Institute of Pathology, Medical Faculty, University of "St. Cyril and Methodius", 1000 Skopje, Macedonia
}

Correspondence should be addressed to Katarina Davalieva; katarina@manu.edu.mk

Received 26 June 2014; Revised 1 August 2014; Accepted 2 August 2014; Published 20 August 2014

Academic Editor: Petra Zürbig

Copyright (C) 2014 Sanja Kiprijanovska et al. This is an open access article distributed under the Creative Commons Attribution License, which permits unrestricted use, distribution, and reproduction in any medium, provided the original work is properly cited.

Proteome analysis of the urine has shown that urine contains disease-specific information for a variety of urogenital system disorders, including prostate cancer ( $\mathrm{PCa}$ ). The aim of this study was to determine the protein components of urine from PCa patients. Urine from 8 patients with clinically and histologically confirmed PCa was analyzed by conventional 2D PAGE. The MS identification of the most prominent 125 spots from the urine map revealed 45 distinct proteins. According to Gene Ontology, the identified proteins are involved in a variety of biological processes, majority of them are secreted (71\%), and half of them are enzymes or transporters. Comparison with the normal urine proteome revealed 11 proteins distinctive for PCa. Using Ingenuity Pathways Analysis, we have found 3 proteins (E3 ubiquitin-protein ligase rififylin, tumor protein D52, and thymidine phosphorylase) associated with cellular growth and proliferation $\left(p=8.35 \times 10^{-4}-3.41 \times 10^{-2}\right)$. The top network of functional associations between 11 proteins was Cell Death and Survival, Cell-To-Cell Signaling and Interaction, and System Development and Function $\left(p=10^{-30}\right)$. In summary, we have created an initial proteomic map of PCa patient's urine. The results from this study provide some leads to understand the molecular bases of prostate cancer.

\section{Introduction}

Urine has become one of the most attractive biofluids in clinical proteomics because it can be obtained in large quantities, can be sampled noninvasively, and does not undergo significant proteolytic degradation compared with other biofluids [1]. The urine contains water, glucose, salt, and proteins derived from plasma or the urogenital tract. It can be viewed as modified ultrafiltrate of plasma combined with proteins derived from kidney and urinary tract, with protein concentration approximately 1000-fold lower than in plasma itself [2].

Even though the urinary proteome is much less complex than the plasma proteome, it contains high number of proteins. The urinary proteome has been studied by almost any proteomics technology. The first proteomic profiling of the normal urine was performed in 1979 using twodimensional electrophoresis (2D) [3]. Afterwards, 2D, liquid chromatography (LC) and capillary electrophoresis (CE), all of them coupled to mass spectrometry (MS), have been used extensively in the proteomics definition of the urine. With the advent of the high throughput proteomics platforms consisting of 1D SDS-PAGE or LC coupled with high resolution mass spectrometers such as LTQ-FT and LTQOrbitrap, the number of detected proteins in healthy urine reached from 1310 to 1823 , depending on the technology used [4-6]. The number of detected proteins in normal urine using $2 \mathrm{D}$ PAGE/MS is relatively lower compared to the proteomics platforms mentioned above [7]. This is mainly due to two reasons: lack of ability to cope with the broad dynamic range of complex samples and with hydrophobic proteins. However, 2D PAGE/MS is still an indispensable 
TABLE 1: Clinical information of patients used to generate urine samples included in the study together with their PSA levels, histology grading and tumor stage.

\begin{tabular}{lcccccc}
\hline Sample number & Patient number & Age & Diagnosis & Tumor stage & Gleason score & Preoperative PSA (ng/mL) \\
\hline 1 & PC-22 & 74 & PCA & pT2c pN0 pM0 & $7(3+4)$ & 8.3 \\
2 & PC-24 & 72 & PCA & pT2c pN0 pM0 & $7(3+4)$ & 5.5 \\
3 & PC-27 & 78 & PCA & pT2c pN0 pM0 & $5(2+3)$ & 4.6 \\
4 & PC-28 & 60 & PCA & pT2c pN0 pM0 & $7(3+4)$ & 7.2 \\
5 & PC-31 & 65 & PCA & pT3b pN1 pM0 & $7(3+4)$ & 8.3 \\
6 & PC-35 & 74 & PCA & pT2c pN0 pM0 & $7(3+4)$ & 22.6 \\
7 & PC-39 & 64 & PCA & pT2b pN1 pM0 & $9(4+5)$ & 50.0 \\
8 & PC-48 & 65 & PCA & pT2c pN0 pM0 & $7(3+4)$ & 32.2 \\
\hline
\end{tabular}

platform in proteomics, particularly for the assessment of the molecular mass of any protein or protein fragments and posttranslational modifications [8].

Qualitative and quantitative changes in urinary proteome often point out to disease-related changes starting from urogenital diseases but also to some systemic diseases [9]. Proteomic analysis of urine has shown that it contains disease-specific information for various diseases. Up till now, urine has been used as a source of biomarkers for a number of kidney diseases and cancers related to the urogenital system such as bladder and prostate cancer, as well as various nonnephrological/urogenital diseases such as preeclampsia, stroke, coronary artery diseases, heart failure, acute appendicitis in children, and graft-versus-host disease reviewed extensively elsewhere $[9,10]$.

In this study, we describe proteomic map of urine from prostate cancer (PCa) patients using 2D PAGE/MS profiling. The determination of urinary proteome of $\mathrm{PCa}$ patients has created an initial database which can be used for comparison to normal urinary proteome database as well as to various cancer diseases urine proteome databases. The results from this study broaden the current knowledge in the field of urinary proteomics and provide some leads to understand the molecular bases of prostate cancer pathophysiology.

\section{Materials and Methods}

2.1. Urine Samples. We analyzed 8 urine samples from patients with PCa prostate obtained from the University Clinic for Urology, University Clinical Centre "Mother Theresa," Skopje, Republic of Macedonia. Informed consent for the use of these samples for research purposes was obtained from the patients in accordance with the Declaration of Helsinki. The study has been approved by the Ethics Committee of the Macedonian Academy of Sciences and Arts.

Patient's clinical records including histology grading, tumor stage, and preoperative prostate-specific antigen (PSA) serum levels were reviewed to preselect the urine samples. Eight urine samples from patients with clinically confirmed and histologically graded tumors were chosen from the urine archive (Table 1), for the 2D PAGE/MS analysis. The preoperative serum PSA levels ranged from 4.6 to $50.0 \mathrm{ng} / \mathrm{mL}$ (mean PSA $=17.1 \pm 16.6)$. The mean age of the selected patients was $69 \pm 6.3$ years and the mean Gleason score was $7.0 \pm 1.1$.

The first morning urine $(3-10) \mathrm{mL}$ was collected from the patients prior to clinical intervention and stored on ice for short period $(<1 \mathrm{~h})$. Samples were centrifuged at $1000 \times \mathrm{g}$, for $10 \mathrm{~min}$, to remove cell debris and casts, aliquoted in $1.5 \mathrm{~mL}$ tubes, and stored at $-80^{\circ} \mathrm{C}$ until use.

2.2. Preparation of Total Protein Extract from Urine. The stored urine samples were thawed and, for each sample, proteins were isolated in triplicate from $100 \mu \mathrm{L}$ urine using 2D Clean-UP Kit (GE Healthcare) according to the manufacturer's instructions. The pellets from each replicate were dissolved in $10 \mu \mathrm{L}$ of UTC buffer ( $8 \mathrm{M}$ urea, $2 \mathrm{M}$ thiourea, $4 \%$ CHAPS), pooled together for each sample, quantified by Bradford method [11] in duplicate against a standard curve of bovine serum albumin (BSA), and stored at $-80^{\circ} \mathrm{C}$ until use.

2.3. 2D PAGE. Pooled samples of total protein extract from urine were used. Equal amounts of proteins from each of the 8 samples were pooled to the total of $400 \mu \mathrm{g}$ of protein per gel. Pooled samples were analyzed in three technical replicates by conventional 2D PAGE analysis on immobilized $\mathrm{pH}$ gradient strips Immobiline DryStrip pH 4-7 (GE Healthcare, Little Chalfont, Buckinghamshire, UK) and 12.5\% SDS PAGE subsequently. For the immobilized $\mathrm{pH}$ gradient strips $\mathrm{pH}$ $4-7$, we have used the rehydration buffer consisting of $8 \mathrm{M}$ urea, $2 \mathrm{M}$ thiourea, 2\% (w/v) CHAPS, $10 \mathrm{mM}$ DTT, $1.2 \%$

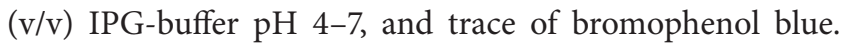
Isoelectric focusing of the rehydrated $24 \mathrm{~cm}$ immobilized $\mathrm{pH}$ gradient strips was performed on Ettan IPGphor 3 system (GE Healthcare, Little Chalfont, Buckinghamshire, UK). The strips were focused until total of $64.5 \mathrm{kVh}$ was reached. The focused proteins in the immobilized $\mathrm{pH}$ gradient strips were immediately equilibrated in two incubation steps, each lasting $15 \mathrm{~min}$, at room temperature. In the first step, the equilibration buffer (6 M urea, 2\% (w/v) SDS, 30\% (v/v) glycerol, $50 \mathrm{mM}$ tris, $\mathrm{pH} 8,6$ ) was supplemented with $1 \%$ (w/v) DTT for reduction, followed by alkylation in the same buffer containing $4.7 \%(\mathrm{w} / \mathrm{v})$ iodoacetamide instead of DTT. The second dimension was carried using Ettan DALTsix system (GE Healthcare, Little Chalfont, Buckinghamshire, UK) at $2.5 \mathrm{~W}$ per gel for $30 \mathrm{~min}$, followed by $16 \mathrm{~W} /$ gel for $4 \mathrm{~h}$. 
2.4. 2D PAGE Imaging and Analysis. The gels were stained with Coomassie G-250. Gels were fixed in 30\% (v/v) ethanol and $2 \%(\mathrm{v} / \mathrm{v})$ phosphoric acid for $30 \mathrm{~min}$ with two exchanges of the fixing solution, washed three times with $2 \%(\mathrm{v} / \mathrm{v})$ phosphoric acid for $10 \mathrm{~min}$ each, balanced in prestaining buffer $\left(12 \%(\mathrm{w} / \mathrm{v})\left(\mathrm{NH}_{4}\right)_{2} \mathrm{SO}_{4}, 2 \%(\mathrm{v} / \mathrm{v})\right.$ phosphoric acid, and $18 \%(\mathrm{v} / \mathrm{v})$ ethanol) for another $30 \mathrm{~min}$, and stained in staining solution $\left(0.01 \%(\mathrm{w} / \mathrm{v}) \mathrm{CBB} \mathrm{G}-250,12 \%(\mathrm{w} / \mathrm{v})\left(\mathrm{NH}_{4}\right)_{2} \mathrm{SO}_{4}, 2 \%\right.$ $(\mathrm{v} / \mathrm{v})$ phosphoric acid, and $18 \%(\mathrm{v} / \mathrm{v})$ ethanol) for $72 \mathrm{~h}$. The gels were stored in the staining solution until the spots of interests were manually picked.

The gels were scanned on an Ettan DIGE imager (GE Healthcare) and the resulting images were analyzed with ImageMaster 2D Platinum 7.0 (GE Healthcare, Little Chalfont, Buckinghamshire, UK) software. ImageMaster Platinum values of smooth, minimum area and saliency were 2 , 5 , and 50, respectively. Exclusion filter ( $\mathrm{vol}>450)$ was applied to remove artificial spots and dust particles.

2.5. Mass Spectrometry: Ingel Tryptic Digestion. Ingel digestion was carried out manually with trypsin. Spots were first destained two times with a mixture of $50 \%(\mathrm{v} / \mathrm{v})$ ACN for $15 \mathrm{~min}$ each and then once with $100 \mathrm{mM} \mathrm{NH}_{4} \mathrm{HCO}_{3}$ and $50 \%$ (v/v) ACN for $15 \mathrm{~min}$. Spots were dried in vacuum centrifuge and then reduced with $100 \mathrm{mM} \mathrm{NH}_{4} \mathrm{HCO}_{3}$ containing $10 \mathrm{mM}$ DTT for $45 \mathrm{~min}$ at $56^{\circ} \mathrm{C}$ and then alkylated with $54 \mathrm{mM}$ iodoacetamide in $100 \mathrm{mM} \mathrm{NH}_{4} \mathrm{HCO}_{3}$ for $30 \mathrm{~min}$ in the dark, at room temperature. Gels pieces were washed with $100 \mathrm{mM}$ $\mathrm{NH}_{4} \mathrm{HCO}_{3}$, shrunk with $50 \% \mathrm{ACN}$ for $15 \mathrm{~min}$, and dried in vacuum centrifuge. Gel particles were rehydrated with $20 \mu \mathrm{L}$ of $0.01 \mu \mathrm{g} / \mu \mathrm{L}$ trypsin proteomics grade (Roche Diagnostics $\mathrm{GmbH}$ ) in digestion buffer (95\% $50 \mathrm{mM} \mathrm{NH} \mathrm{NCO}_{3} / 5 \%$ $\mathrm{ACN}$ ) for $45 \mathrm{~min}$ at room temperature. The remaining enzyme supernatant was replaced with one gel volume of the digestion buffer and digestion was carried out at $37^{\circ} \mathrm{C}$, overnight. After digestion, peptides were collected in separate tube, extracted once with $20 \mu \mathrm{L}$ of $50 \%$ ACN and twice with a mixture of $50 \% \mathrm{ACN} / 5 \%$ formic acid, dried in vacuum centrifuge, and reconstituted in $10 \mu \mathrm{L}$ of $0.1 \%$ TFA.

2.6. Mass Spectrometry: Identification. For MS analysis, peptides were purified using ZipTip $_{\mathrm{C} 18}$ (Millipore Corporation) following the manufacturer's instructions and eluted in $2-3 \mu \mathrm{L}$ of $\mathrm{CHCA}(4 \mathrm{mg} / \mathrm{mL}$ in $50 \% \mathrm{ACN} / 0.1 \% \mathrm{TFA})$ directly onto a MALDI target plate (Shimadzu Biotech Kratos Analytical). Droplets were allowed to dry at room temperature. Samples analysis was performed using AXIMA Performance MALDI-TOF-TOF mass spectrometer (Shimadzu Biotech Kratos Analytical). Spectra acquisition and processing were performed using the MALDI-MS software (Shimadzu Biotech Kratos Analytical) version 2.9.3.20110624 in positive reflectron mode at mass range $1-5000 \mathrm{Da}$ with a low mass gate at $500 \mathrm{Da}$ and pulsed extraction optimized at $2300 \mathrm{Da}$. External calibration was performed based on monoisotopic values of five well-defined peptides: bradykinin fragment 1-5, angiotensin II human, [Glu1]-gibrinopeptide B human, adrenocorticotropic hormone fragment 1-17 human, and adrenocorticotropic hormone fragment 7-38 human
(Sigma-Aldrich). External calibration mix (500 fmol/ $\mu \mathrm{L}$ ) was diluted with the matrix in ratio $1: 1$ and applied onto the MALDI target plate at final concentration of 250 fmol per spot. Each mass spectrum was acquired by 500 laser profiles (five pulses per profile) collected across the whole sample. After filtering tryptic-, keratin-, and matrixcontaminant peaks, the resulting monoisotopic list of $\mathrm{m} / \mathrm{z}$ values was submitted to the search engine Mascot (version 2.4.01, MatrixScience, UK) searching all human proteins and sequence information from Swiss-Prot (version 2014_05, 20265 sequences) and NCBInr (version 20140323, 276505 sequences). The following search parameters were applied: fixed modification-carbamidomethylation and variable modifications-methionine oxidation and N-terminal acetylation. Up to 1 missed tryptic cleavage was permitted and peptide mass tolerance of $\pm 0.40 \mathrm{Da}$ was used for all mass searches. Positive identification was based on a Mascot score greater than 56, above the significance level $(P<0.05)$. The reported proteins were always those with the highest number of peptide matches.

2.7. Functional Characterization of the Identified Proteins. For an overview of the cellular localization, molecular function, and biological processes in which identified proteins are included, we used the UniProt Knowledgebase (UniProtKB) and Gene Ontology (GO) database. The accession numbers of the identified proteins were imported into Ingenuity Pathway Analysis (IPA) (Ingenuity Systems, USA) and functionally assigned to canonical pathways and the most significant networks generated from previous publications and public protein interaction databases. A $P$ value calculated with the right-tailed Fisher's exact test was used to yield a network's score and to rank networks according to their degree of association with our data set.

\section{Results}

For this study, we selected urine samples from 8 patients with clinically and histologically confirmed PCa cancer (Table 1). The mean age of the selected patients was 69 years $( \pm 6.3)$, the mean Gleason score was $7.0( \pm 1.1)$, and the mean preoperative serum PSA level was $17.1( \pm 16.6)$. The average amount of purified proteins from $100 \mu \mathrm{L}$ urine ranged from 18.2 to $29.8 \mu \mathrm{g}$. The analysis of each patient urine proteome required substantial number of isolations and $2 \mathrm{D}$ PAGE gels for analysis. Therefore, we used pooled samples of total protein extract from 8 patients. The pooled samples also give more relevant picture of the PCa patient's urine proteome.

Following 2D PAGE and staining, $1085 \pm 110$ spots were detected and 948 of them were reproducibly visualized in the three technical replicates (Figure 1(a)). The most prominent 125 spots were picked up for the MS analysis. The position of these spots in the 2D urine map is shown in Figure 1(b). The MS identification of these spots revealed that they belong to 45 distinct proteins (Table 2). A number of proteins were presented on 2D map as a horizontal row of multiple spots (with small changes in pI and molecular weight), likely caused by variable posttranslational modifications (PTMs). 

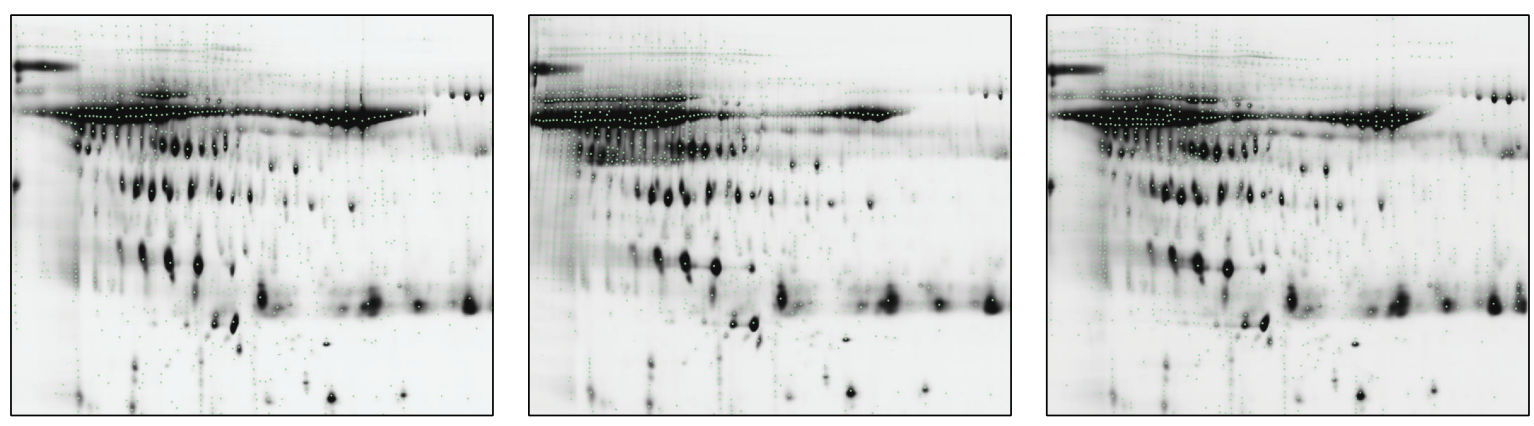

(a)

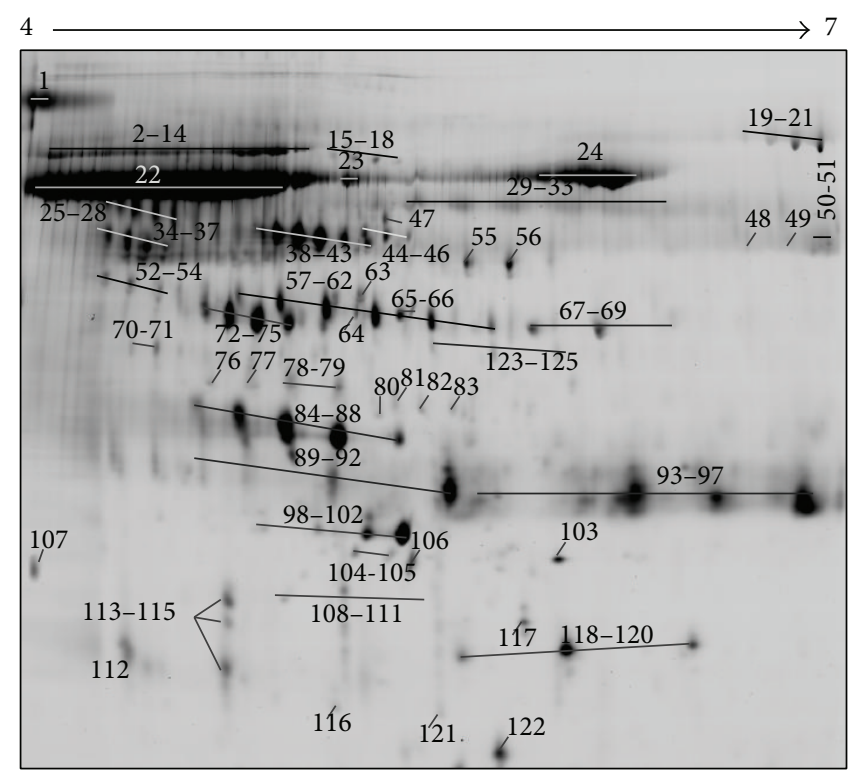

(b)

FIGURE 1: 2D maps of the urine proteome from PCa patients obtained by 2D electrophoresis using IEF on pH 4-7 IPG strip and 12.5\% SDSPAGE. (a) Images of the three technical replicates of the pooled urine protein samples. The detected spots in the images are represented with green dots. Overall, 948 spots were reproducibly visualised in the three maps. (b) Representative 2D map of the urine proteome. All identified protein spots are marked with numbered arrows. Details of these proteins identified by MALDI MS are tabulated in Table 2.

All identified proteins were in the expected molecular size $(14-80 \mathrm{kDa})$ and $\mathrm{pI}$ value (4.93 to 8.07$)$ and the majority of it were high-molecular weight proteins $(>30 \mathrm{kDa})$. Representative 2D map showed no evidence of protein degradation that usually presents as vertical streaking of the protein stain.

The identified proteins from PCa patient's urine were classified by subcellular location, molecular function, biological function, and type of protein using the available data from the UniProt Knowledgebase (UniProtKB) and Gene Ontology (GO) database (Figure 2). Regarding molecular function, $53 \%$ of all identified proteins in PCa patient's urine have binding function, followed by transport and catalytic activity. Approximately half of the identified proteins are involved in regulation of biological processes, developmental processes, and cellular processes. Half of the proteins were enzymes and transporters and the rest belonged to transcription regulators, growth factors, cytokines, and other protein types. The majority of the identified proteins (71\%) were secreted and had extracellular space location.
Comparison of the identified 45 proteins with proteins identified in normal urine by 2D PAGE/MS [7] showed that 34 proteins are found in the normal urine as well, while 11 have not been reported. The functional characteristics of the 11 proteins are given in Table 3.

Using Ingenuity Pathways Analysis (IPA) classification and networking, we found out that some of the 11 identified proteins in $\mathrm{PCa}$ are significantly associated with cancer and organism injury and abnormalities diseases and disorders. Four proteins (antithrombin-III, transmembrane and immunoglobulin domain-containing protein 1, tumor protein D52, and thymidine phosphorylase) are associated with different types of cancers $\left(p=4.17 \times 10^{-4}-3.21 \times\right.$ $10^{-2}$ ), while 2 proteins (antithrombin-III and thymidine phosphorylase) are associated with organism injury and abnormalities $\left(p=8.35 \times 10^{-4}-4.54 \times 10^{-2}\right)$. In the molecular and cellular function classification, we have found 3 proteins (E3 ubiquitin-protein ligase rififylin, tumor protein D52, and thymidine phosphorylase) associated with cellular 

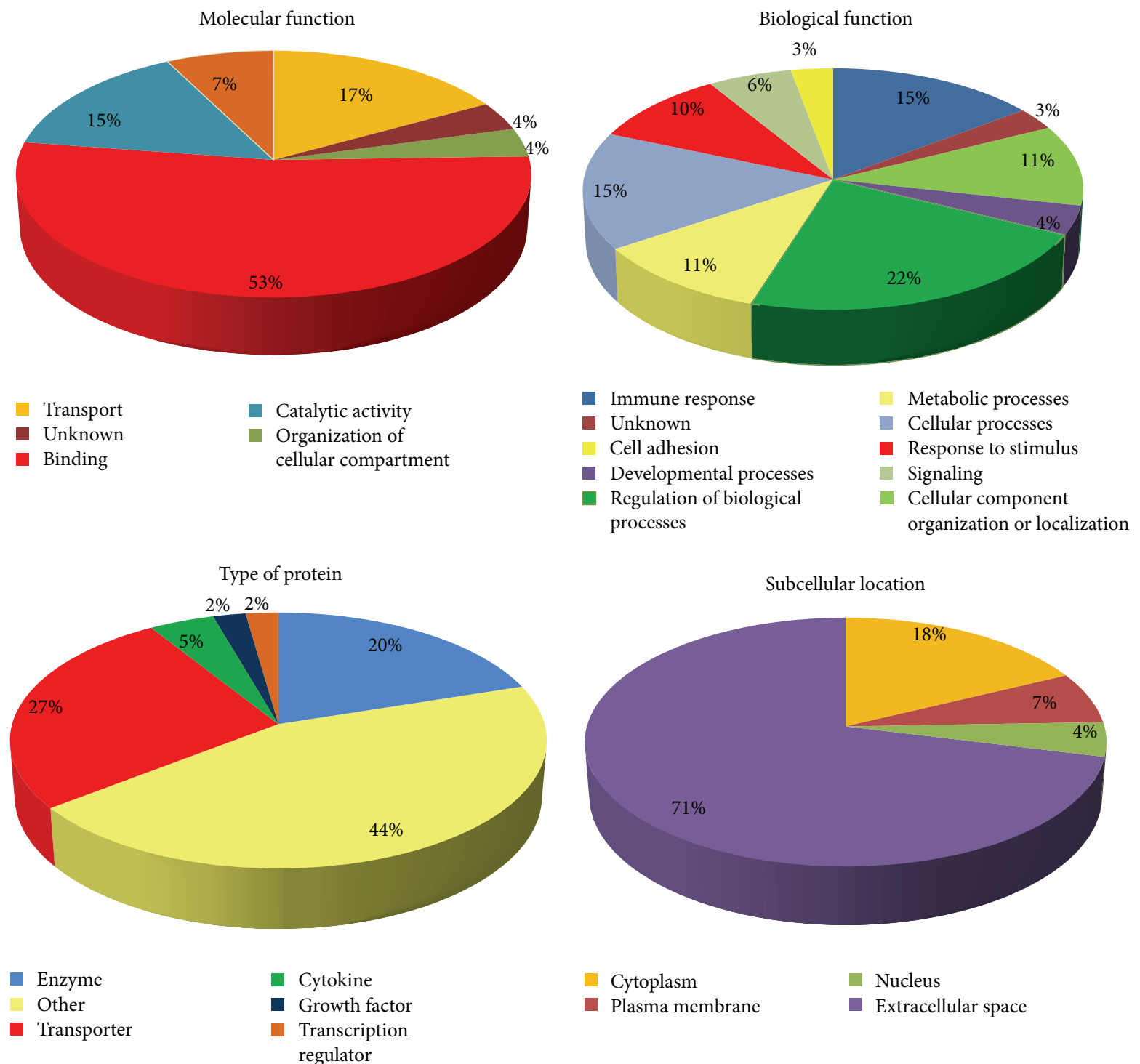

- Plasma membrane Extracellular space

Figure 2: Classification of the identified proteins in urine of PCa patients. The molecular function, biological processes in which they are involved, subcellular location, and type of protein were assessed by Gene Ontology search.

growth and proliferation $\left(p=8.35 \times 10^{-4}-3.41 \times 10^{-2}\right)$. The top protein network of functional associations between proteins was Cell Death and Survival, Cell-To-Cell Signaling and Interaction, and System Development and Function with score $30\left(p=10^{-30}\right)$. The network encompassed 10 from 11 proteins closely connected through four major nodes: ubiquitin $\mathrm{C}$ (UBC), tumor necrosis factor (TNF), transforming growth factor beta 1 (TGFB1), and interferon gamma (IFNG) (Figure 3).

\section{Discussion}

Determination of protein map and composition of $\mathrm{PCa}$ patient's urine may lead to an increased understanding of cancer pathophysiology. Using 2D PAGE/MALDI-TOF, we have identified a total of 125 protein spots belonging to 45 unique proteins in $\mathrm{PCa}$ patient's urine. According to the molecular and functional data for these proteins, they can be classified into several groups: kidney secretory and structural proteins: uromodulin (formerly Tamm-Horsfall protein), vesicular integral-membrane protein (VIP), gelsolin, and actin cytoplasmic 1 and 2, basement membrane-specific heparin sulphate proteoglycan core protein; serum constitutional and transport proteins: albumin, vitamin $\mathrm{D}$ binding protein, leucine-rich $\alpha 2$ glycoprotein, transthyretin, plasma retinol-binding protein, haptoglobin B chain, ubiquitin, $\alpha$ 1 acid glycoprotein 1 , and tumor protein D52; coagulation factors: fibrinogen $\alpha$ chain, kininogen-1, fibrinogen $\beta$ chain, fibrinogen $\gamma$ chain, CD59 glycoprotein, and antithrombinIII; complement fractions: mannan-binding lectin serine protease, immunoglobulins with heavy and light chains, secreted and transmembrane protein 1, protein AMBP, and transmembrane and immunoglobulin domain-containing protein 1; proteases and inhibitors: $\alpha 1$ antitrypsin and $\alpha 1$ antitrypsin 


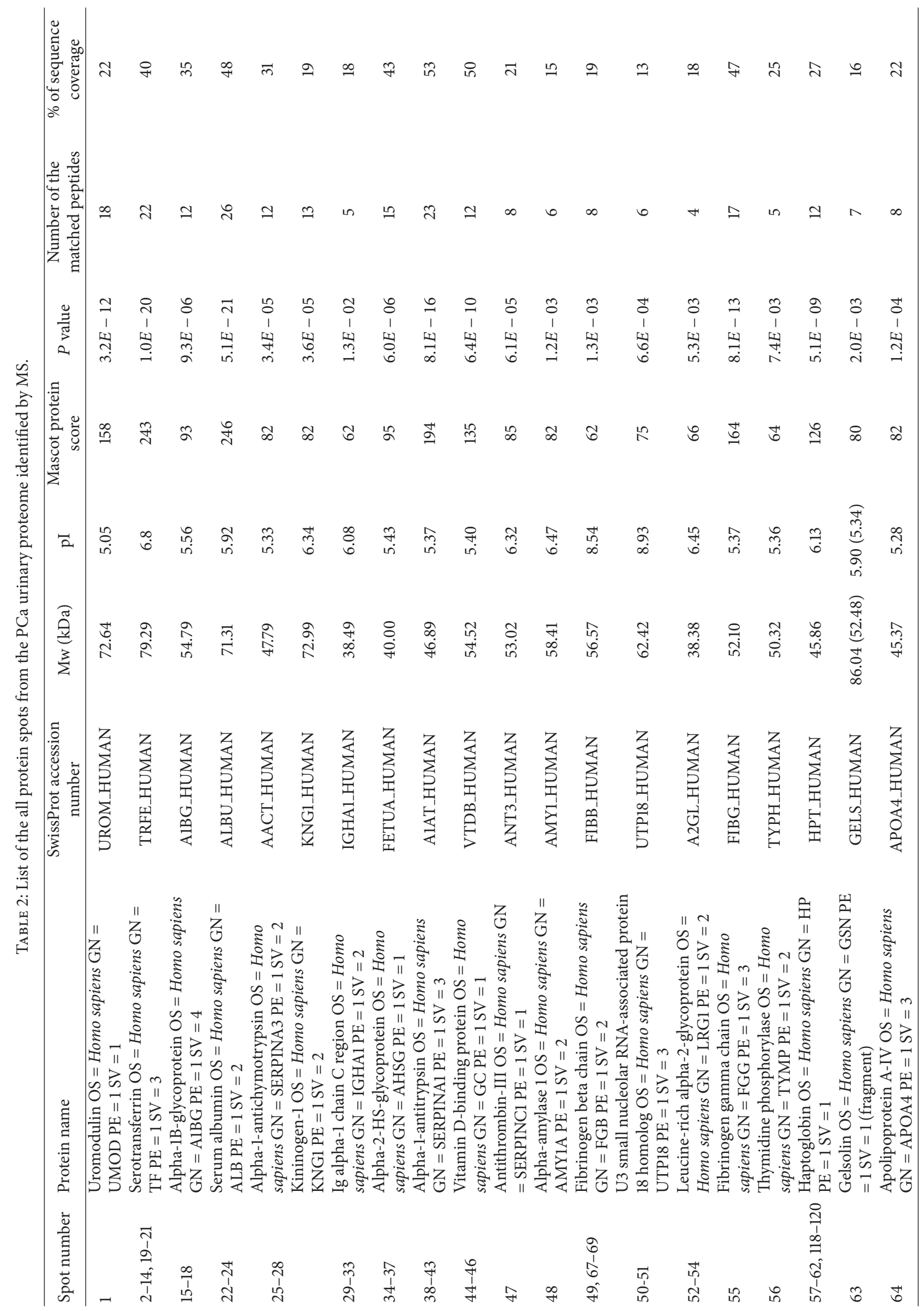




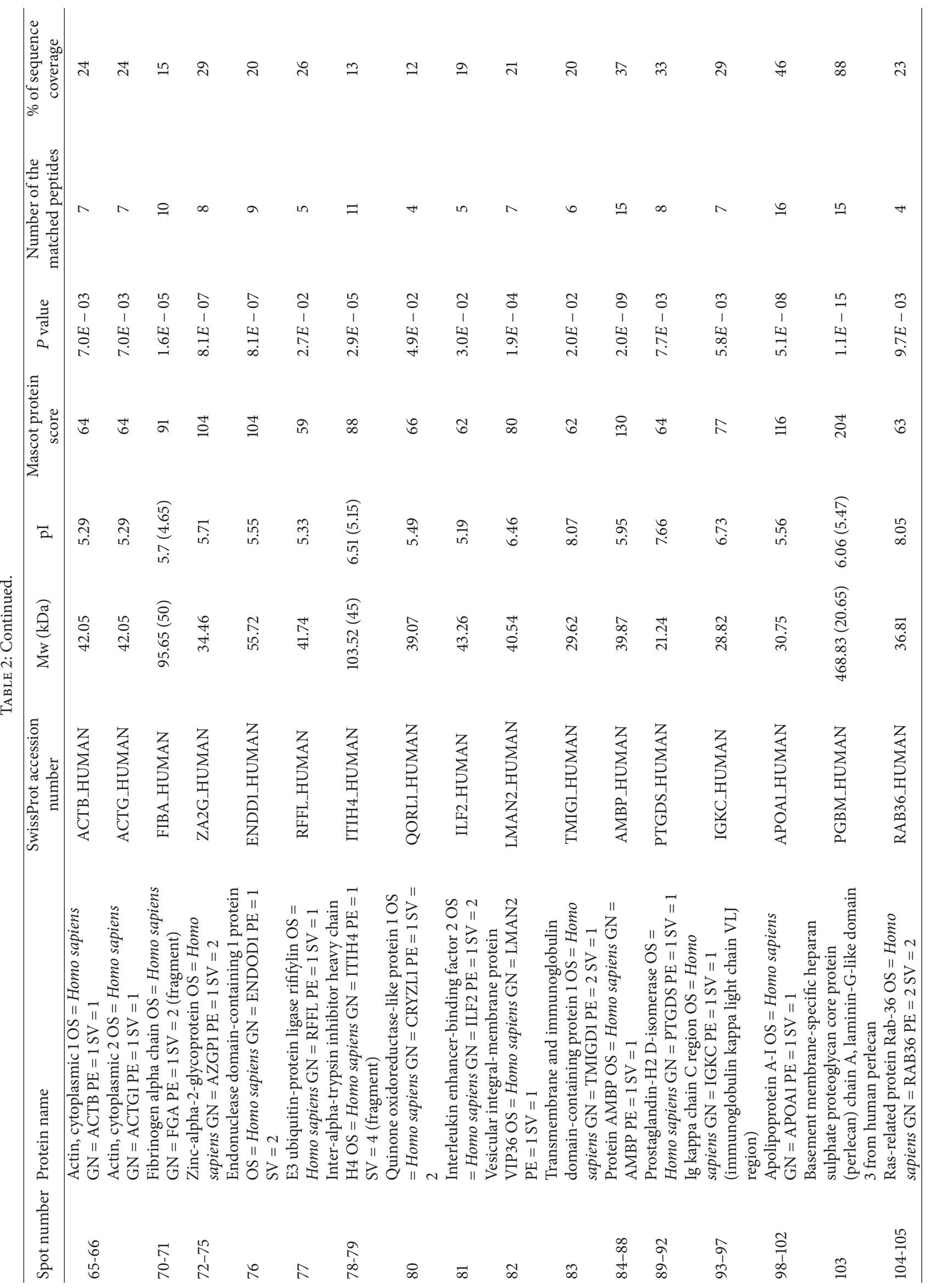




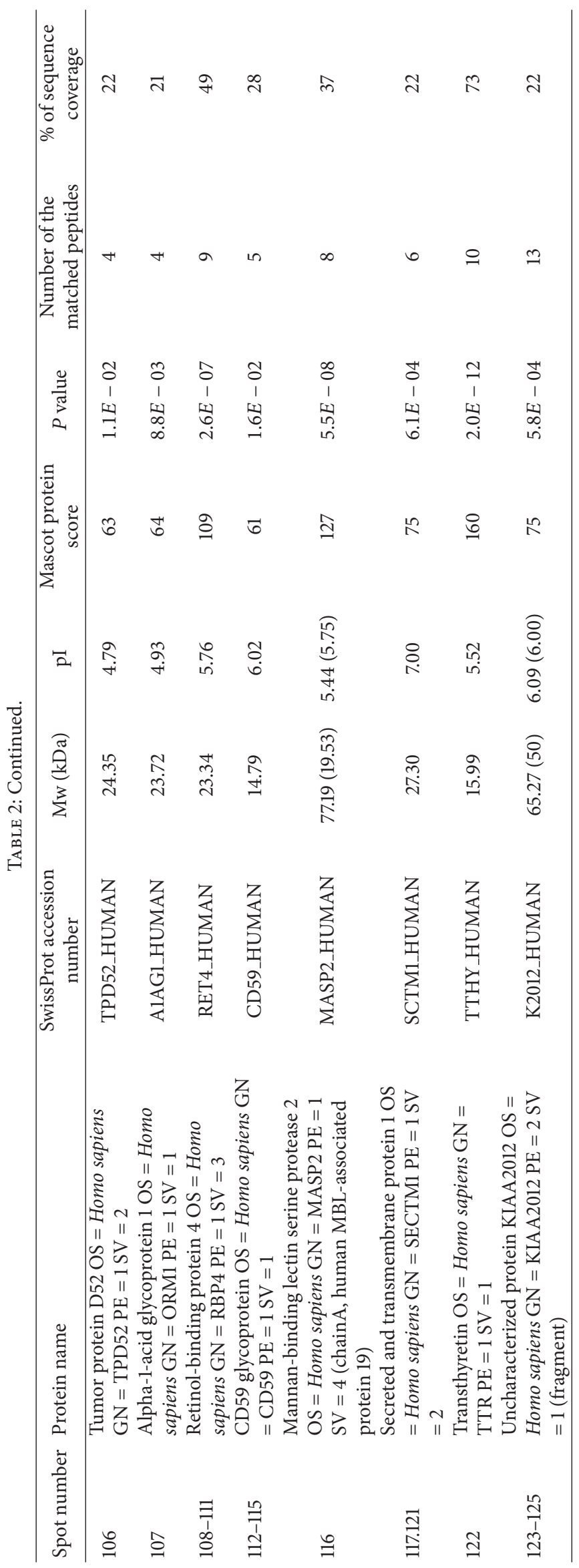




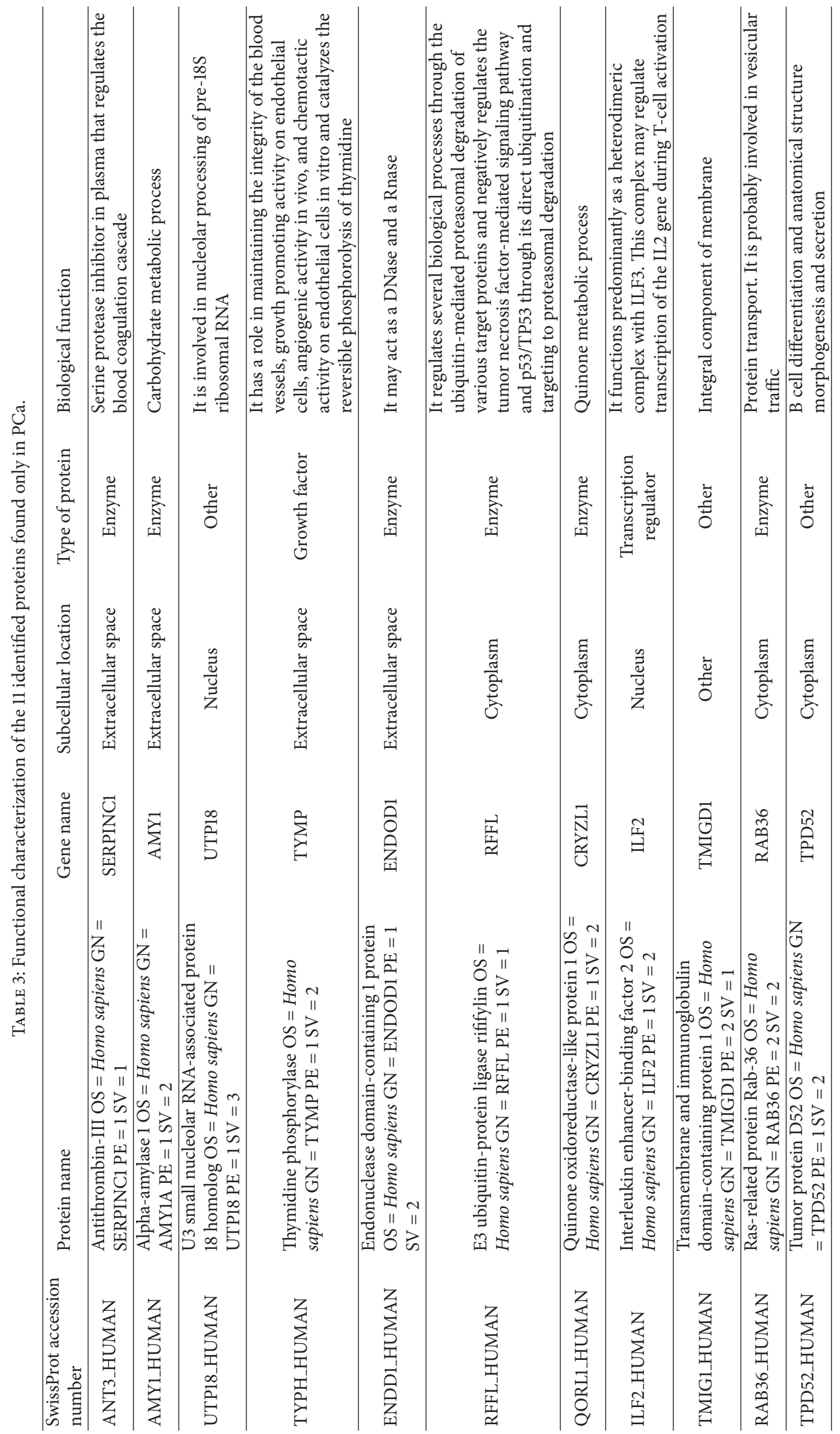




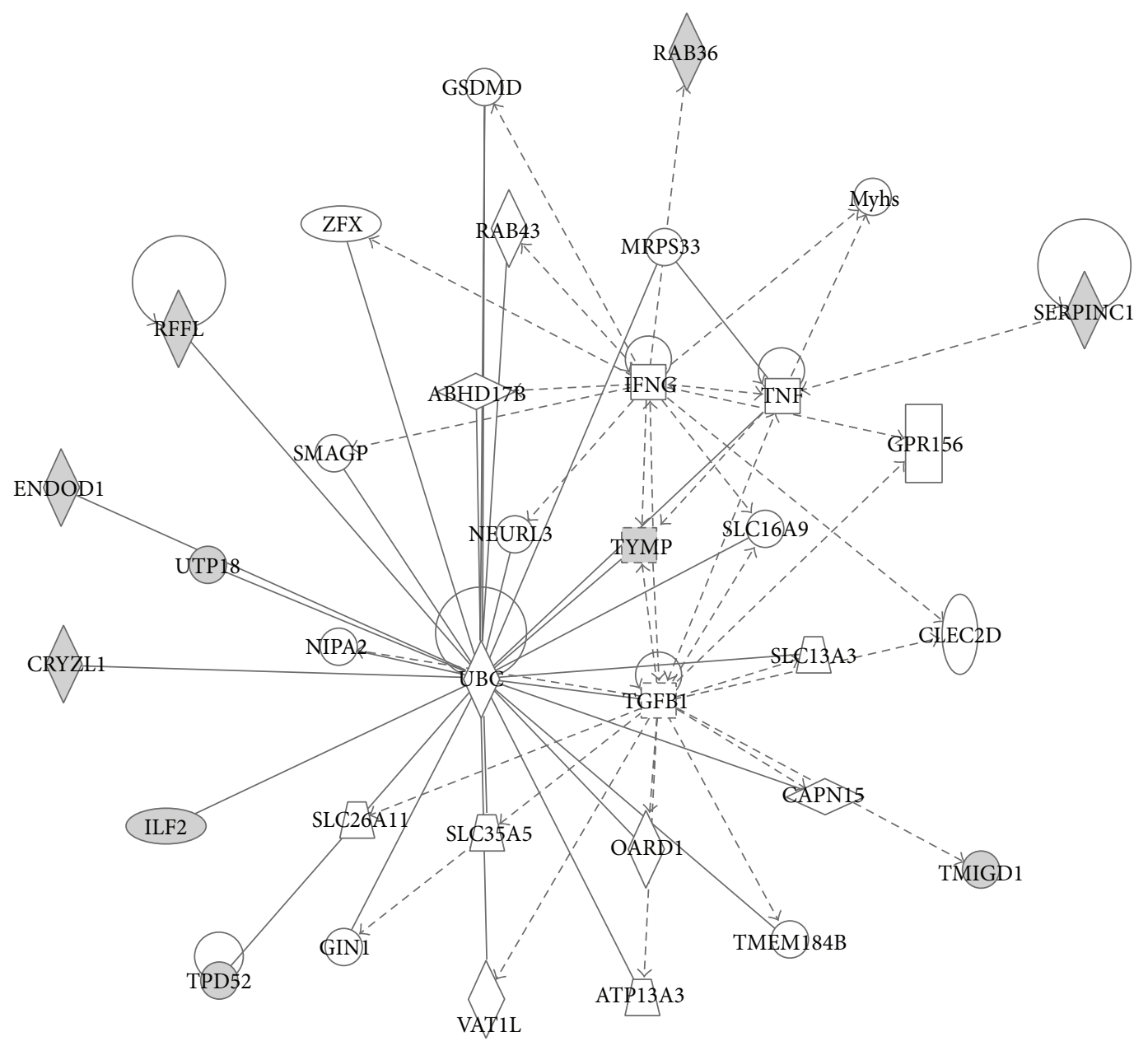

FIGURE 3: Network associated with the 11 urinary proteins from patients with PCa according to IPA. Top protein network of functional associations between proteins was Cell Death and Survival, Cell-To-Cell Signaling and Interaction, and System Development and Function with score $30\left(p=10^{-30}\right)$. The proteins are connected through four major nodes: ubiquitin (UBC) and cytokines, TNF, TGFB1, and IFNG. The proteins identified in this study are represented with gene names (for protein name, please see Table 3 ) and coloured in gray. The network is graphically displayed with proteins as nodes and the biological relationships between the nodes as lines. Different shapes represent the functional classes of proteins. The length of a line reflects published evidence supporting the node-to-node relationship concerned.

fragment, $\alpha 1$ antichymotrypsin, and inter- $\alpha$ trypsin inhibitor heavy chain $\mathrm{H} 4$; enzymes: prostaglandin-H2-isomerase, alpha-amylase 1, thymidine phosphorylase, endonuclease domain-containing 1 protein, quinone oxidoreductase-like protein 1, E3 ubiquitin-protein ligase rififylin, and Ras-related protein Rab-36; metal binding proteins: serum transferrin, $\alpha$ HS-glycoprotein, and zinc- $\alpha$-2-glycoprotein; transcriptional regulators: U3 small nucleolar RNA-associated protein 18 and interleukin enhancer-binding factor 2; and lipoprotein metabolism: apolipoprotein.

Regarding the subcellular location of the identified proteins, our analysis revealed that extracellular proteins and plasma membrane proteins represent the majority in the PCa patient's urine. This was expected for two reasons: first, the urine is in direct contact with several glands in the male urinary tract, and, second, substantial fraction of the urinary proteins is derived from plasma [4, 7]. Among diverse biological functions in which the identified set of urinary proteins is involved, signal transducer activity was unexpected as this function was not present in the observed proportion in proteins from the plasma proteome [4]. On the other hand, it was expected that the PCa patient's urine contains substantial amount of immune response proteins, proteins involved in response to stimuli, signalling and adhesion molecules, as cancers may be considered a state of constant inflammation of the organism [12].

Thirty-four proteins in our study have been reported as constituents of the normal urine, while 11 proteins (antithrombin-III, alpha-amylase 1, U3 small nucleolar RNAassociated protein 18 homolog, thymidine phosphorylase, endonuclease domain-containing 1 protein, E3 ubiquitinprotein ligase rififylin, quinone oxidoreductase-like protein 1 , interleukin enhancer-binding factor 2 , transmembrane and immunoglobulin domain-containing protein 1, Ras-related protein Rab-36, and Tumor protein D52) were not reported in the normal urine proteome [7]. Of them, thymidine phosphorylase, E3 ubiquitin-protein ligase, and tumor protein D52 are involved in processes of angiogenesis, tumor 
growth, or metastasis and the rest are proteins with different physiological functions and no reported involvement in cancer development or progression. IPA analysis of the 11 proteins also pointed out these 3 proteins as significantly associated with cellular growth and proliferation.

Thymidine phosphorylase (TYMP) is an enzyme involved in pyrimidine metabolism and also known to be a platelet-derived endothelial cell growth factor (PD-ECGF). TYMP is overexpressed in various tumors including prostate cancer and plays an important role in angiogenesis, tumor growth invasion, and metastasis [13]. E3 ubiquitin-protein ligase (RFFL) has been implicated in regulation of p53 tumor suppressor stability $[14,15]$. Major physiological function of RFFL is promotion of $\mathrm{p} 53$ destruction and, as a result of it, it is frequently found overexpressed in a variety of human cancers [16]. The tumor protein D52 (TPD52) is frequently and strongly upregulated in many human cancer types and this trend is observed in various urogenital cancers among which is prostate cancer as well [17].

Furthermore, IPA analysis pointed out functional associations between the 11 proteins. The network encompassed 10 out of 11 proteins connected through four nodes: ubiquitin $\mathrm{C}$ (UBC), tumor necrosis factor (TNF), transforming growth factor beta 1 (TGFB1), and interferon gamma (IFNG). Ubiquitination has been associated with protein degradation, DNA repair, cell cycle regulation, kinase modification, endocytosis, and regulation of other cell signaling pathways $[18,19]$. Human neurodegenerative, infectious diseases and tumorigenesis have been associated with alterations in ubiquitin pathways [20]. Ubiquitin has been detected in a variety of normal and cancerous tissues. Variations in the distribution and intensity of ubiquitin in benign and malignant conditions of the human prostate have been observed, leading to conclusion that it has implication in tumor pathogenesis of prostate cancer [21]. Our results are in concordance with this finding since seven out of ten proteins in the network, found in $\mathrm{PCa}$, are directly connected to UBC.

The rest of the regulatory nodes in the network are represented by cytokines (TFN, TGFB1, and IFNG). Cytokines are regulators of host responses to infection, immune responses, inflammation, and trauma [22]. The biological activity of these cytokines is conventionally associated with antitumor mechanisms during cell-mediated adaptive immune response. Despite this, a number of reports suggest that their role in carcinogenesis is complex, having both tumor suppressor and oncogenic activities [23-25].

The interaction of ubiquitin, cytokines, and urine proteins found in PCa patients in this study, as proposed by IPA network, having in mind dual nature of cytokines and ubiquitin in the cancer progression, may lead to deeper understanding of prostate cancer pathogenesis. The possible role of these proteins and their connection with the signal transduction cascade of prostate cancer remains to be solved in the future.

\section{Conclusions}

In summary, we have created an initial proteomic map of PCa patient's human urine. The most prominent spots were successfully identified and analyzed in context of prostate cancer. Comparison with other published studies analyzing normal urine proteome pointed out several proteins that might have some role in the pathogenesis of prostate cancer. Moreover, IPA analysis showed significant association of our proteins with cancer and cellular growth and proliferation. The attempts to identify more low-abundant proteins in the urine from PCa patients by different strategies as well as comparison with urinary proteome from different cancer are underway. Although the presented urinary proteome map from patients with $\mathrm{PCa}$ showed limited number of proteins, the information regarding their position, molecular mass, possible posttranslational modifications, and presence of different protein fragments are useful addition to the present knowledge and provide some leads to understand the molecular bases of prostate cancer pathophysiology.

\section{Abbreviations}

$\begin{array}{ll}\text { 1D: } & \text { One-dimensional } \\ \text { 2D: } & \text { Two-dimensional } \\ \text { TwAGE: } & \begin{array}{l}\text { Two-dimensional polyacrylamide gel } \\ \text { electrophoresis }\end{array} \\ \text { ACN: } & \text { Acetonitrile } \\ \text { BSA: } & \text { Bovine serum albumin } \\ \text { CHAPS: } & \text { 3-[(3-Cholamidopropyl) } \\ & \text { dimethylammonio]-1- } \\ \text { Da: } & \text { propanesulfonate } \\ \text { DTT: } & \text { Dalton } \\ \text { GO: } & \text { Dithiothreitol } \\ \text { IAA: } & \text { Gene Ontology } \\ \text { IPA: } & \text { 2-Iodoacetamide } \\ \text { LC: } & \text { Ingenuity Pathways Analysis } \\ \text { MALDI-TOF-TOF: } & \text { Matrix-assisted laser } \\ & \text { desorption/ionization-time of } \\ & \text { flight-time of flight } \\ \text { MS: } & \text { Mass spectrometry } \\ \text { PSA: } & \text { Prostate-specific antigen } \\ \text { SDS: } & \text { Sodium dodecyl sulfate } \\ \text { SDS-PAGE: } & \text { Sodium dodecyl sulfate } \\ \text { TFA: } & \text { polyacrylamide gel electrophoresis } \\ \text { Tris: } & \text { Trifluoroacetic acid } \\ \text { UniProtKB: } & \text { Tris(hydroxymethyl)aminomethane } \\ & \text { UniProt Knowledgebase. } \\ & \end{array}$

\section{Conflict of Interests}

The authors declare that there is no conflict of interests regarding the publication of this paper.

\section{Acknowledgments}

This work was supported by the funds for Science of the Macedonian Academy of Sciences and Arts (Grant no. 09114/1, Biomarker Detection in Prostate Cancer with the Use of 2D-DIGE/MALDI MS Technology). The authors thank patients for the participation in the study, medical personnel 
at the University Clinic for Urology at the University Clinical Centre "Mother Theresa," Skopje, Republic of Macedonia, for the collection of urine samples, and Katerina Markovska for the technical assistance.

\section{References}

[1] S. Decramer, A. G. de Peredo, B. Breuil et al., "Urine in clinical proteomics," Molecular and Cellular Proteomics, vol. 7, no. 10, pp. 1850-1862, 2008.

[2] G. L. Hortin and D. Sviridov, "Diagnostic potential for urinary proteomics," Pharmacogenomics, vol. 8, no. 3, pp. 237-255, 2007.

[3] N. G. Anderson, N. L. Anderson, and S. L. Tollaksen, "Proteins in human urine. I. Concentration and analysis by twodimensional electrophoresis," Clinical Chemistry, vol. 25, no. 7, pp. 1199-1210, 1979.

[4] J. Adachi, C. Kumar, Y. Zhang, J. V. Olsen, and M. Mann, “The human urinary proteome contains more than 1500 proteins, including a large proportion of membrane proteins," Genome Biology, vol. 7, no. 9, article R80, 2006.

[5] Q. R. Li, K. X. Fan, R. X. Li et al., "A comprehensive and nonprefractionation on the protein level approach for the human urinary proteome: touching phosphorylation in urine," Rapid Communications in Mass Spectrometry, vol. 24, no. 6, pp. 823832, 2010.

[6] A. Marimuthu, R. N. O’Meally, R. Chaerkady et al., "A comprehensive map of the human urinary proteome," Journal of Proteome Research, vol. 10, no. 6, pp. 2734-2743, 2011.

[7] G. Candiano, L. Santucci, A. Petretto et al., "2D-electrophoresis and the urine proteome map: where do we stand?" Journal of Proteomics, vol. 73, no. 5, pp. 829-844, 2010.

[8] S. Magdeldin, S. Enany, Y. Yoshida et al., "Basics and recent advances of two dimensional-polyacrylamide gel electrophoresis," Clinical Proteomics, vol. 11, no. 1, article 16, 2014.

[9] E. R. Suárez, J. Siwy, P. Zürbig, and H. Mischak, "Urine as a source for clinical proteome analysis: from discovery to clinical application," Biochimica et Biophysica Acta, vol. 1844, no. 5, pp. 884-898, 2014.

[10] A. Albalat, H. Mischak, and W. Mullen, "Clinical application of urinary proteomics/peptidomics," Expert Review of Proteomics, vol. 8, no. 5, pp. 615-629, 2011.

[11] M. M. Bradford, "A rapid and sensitive method for the quantitation of microgram quantities of protein utilizing the principle of protein dye binding," Analytical Biochemistry, vol. 72, no. 1-2, pp. 248-254, 1976.

[12] C. Gabay and I. Kushner, "Acute-phase proteins and other systemic responses to inflammation," The New England Journal of Medicine, vol. 340, no. 6, pp. 448-454, 1999.

[13] S. Akiyama, T. Furukawa, T. Sumizawa et al., "The role of thymidine phosphorylase, an angiogenic enzyme, in tumor progression," Cancer Science, vol. 95, no. 11, pp. 851-857, 2004.

[14] R. Honda, H. Tanaka, and H. Yasuda, "Oncoprotein MDM2 is a ubiquitin ligase E3 for tumor suppressor p53," The FEBS Letters, vol. 420, no. 1, pp. 25-27, 1997.

[15] J. D. Oliner, J. A. Pietenpol, S. Thiagalingam, J. Gyuris, K. W. Kinzler, and B. Vogelstein, "Oncoprotein MDM2 conceals the activation domain of tumour suppressor p53," Nature, vol. 362, no. 6423 , pp. $857-860,1993$.
[16] E. Meulmeester, Y. Pereg, Y. Shiloh, and A. G. Jochemsen, "ATM-mediated phosphorylations inhibit Mdmx/Mdm2 stabilization by HAUSP in favor of p53 activation," Cell Cycle, vol. 4, no. 9, pp. 1166-1170, 2005.

[17] P. Tennstedt, C. Bolch, G. Strobel et al., "Patterns of TPD52 overexpression in multiple human solid tumor types analyzed by quantitative PCR," International Journal of Oncology, vol. 44, no. 2, pp. 609-615, 2014.

[18] M. J. Clague and S. Urbé, "Ubiquitin: same molecule, different degradation pathways," Cell, vol. 143, no. 5, pp. 682-685, 2010.

[19] D. Mukhopadhyay and H. Riezman, "Proteasome-independent functions of ubiquitin in endocytosis and signaling," Science, vol. 315, no. 5809, pp. 201-205, 2007.

[20] B. M. Kessler, "Ubiquitin-omics reveals novel networks and associations with human disease," Current Opinion in Chemical Biology, vol. 17, no. 1, pp. 59-65, 2013.

[21] Z. M. Bataineh and O. Habbal, "Immunoreactivity of ubiqitin in human prostate gland," Neuroendocrinology Letters, vol. 27, no. 4, pp. 517-522, 2006.

[22] C. A. Dinarello, "Proinflammatory cytokines," Chest, vol. 118, no. 2, pp. 503-508, 2000.

[23] L. Bertazza and S. Mocellin, "The dual role of tumor necrosis factor (TNF) in cancer biology," Current Medicinal Chemistry, vol. 17, no. 29, pp. 3337-3352, 2010.

[24] M. P. de Caestecker, E. Piek, and A. B. Roberts, "Role of transforming growth factor- $\beta$ signaling in cancer," Journal of the National Cancer Institute, vol. 92, no. 17, pp. 1388-1402, 2000.

[25] M. R. Zaidi and G. Merlino, "The two faces of interferon- $\gamma$ in cancer," Clinical Cancer Research, vol. 17, no. 19, pp. 6118-6124, 2011. 

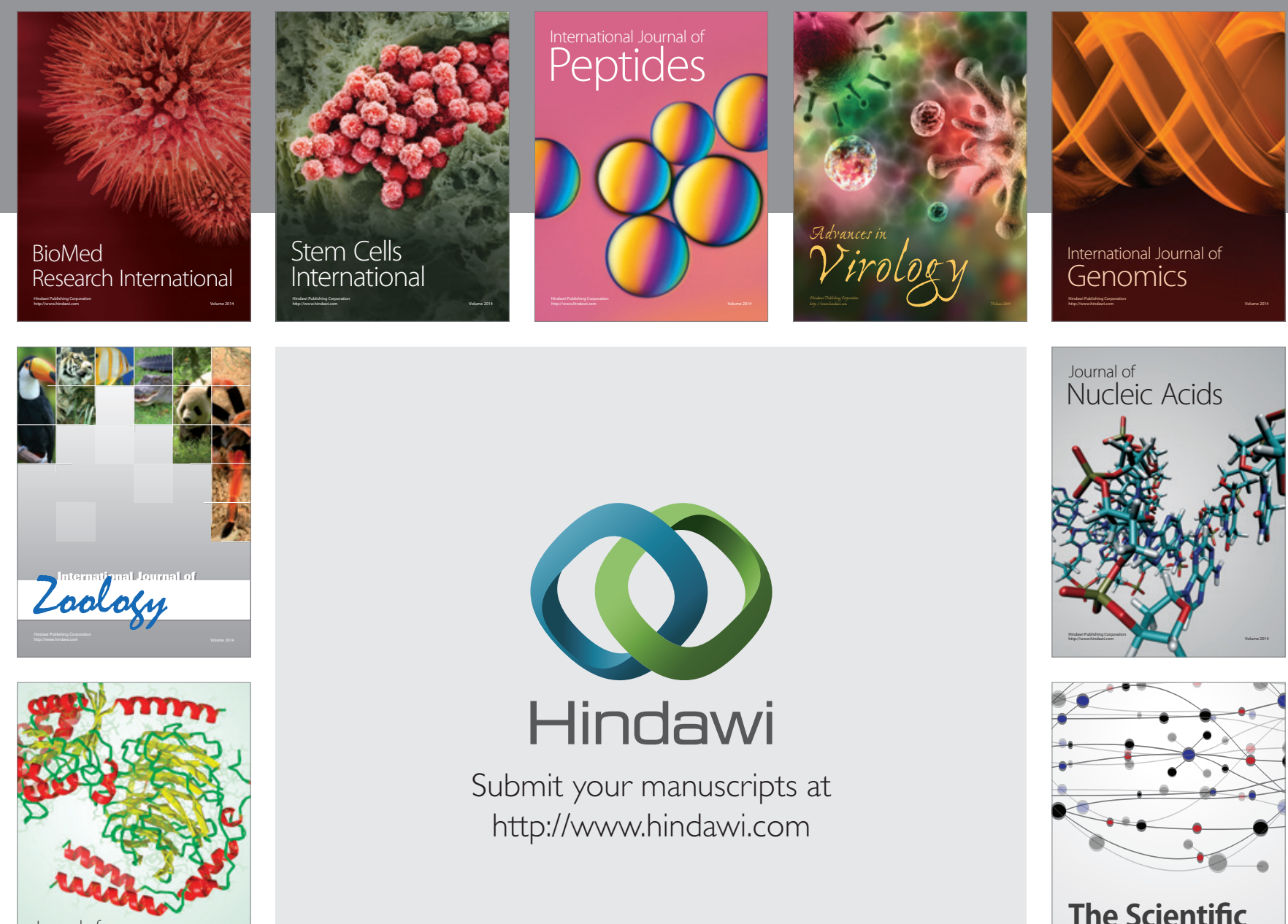

Submit your manuscripts at

http://www.hindawi.com

Journal of
Signal Transduction
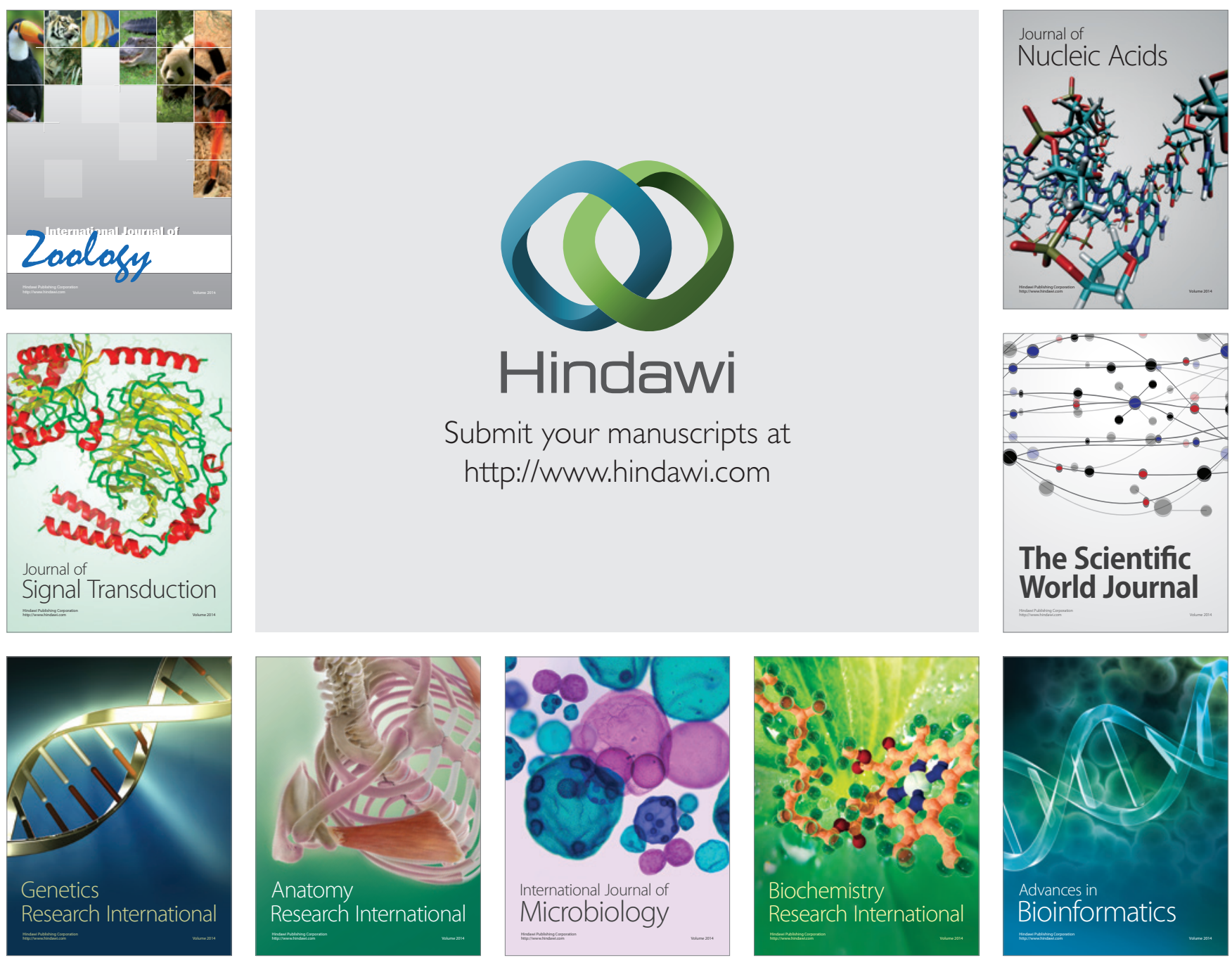

The Scientific World Journal
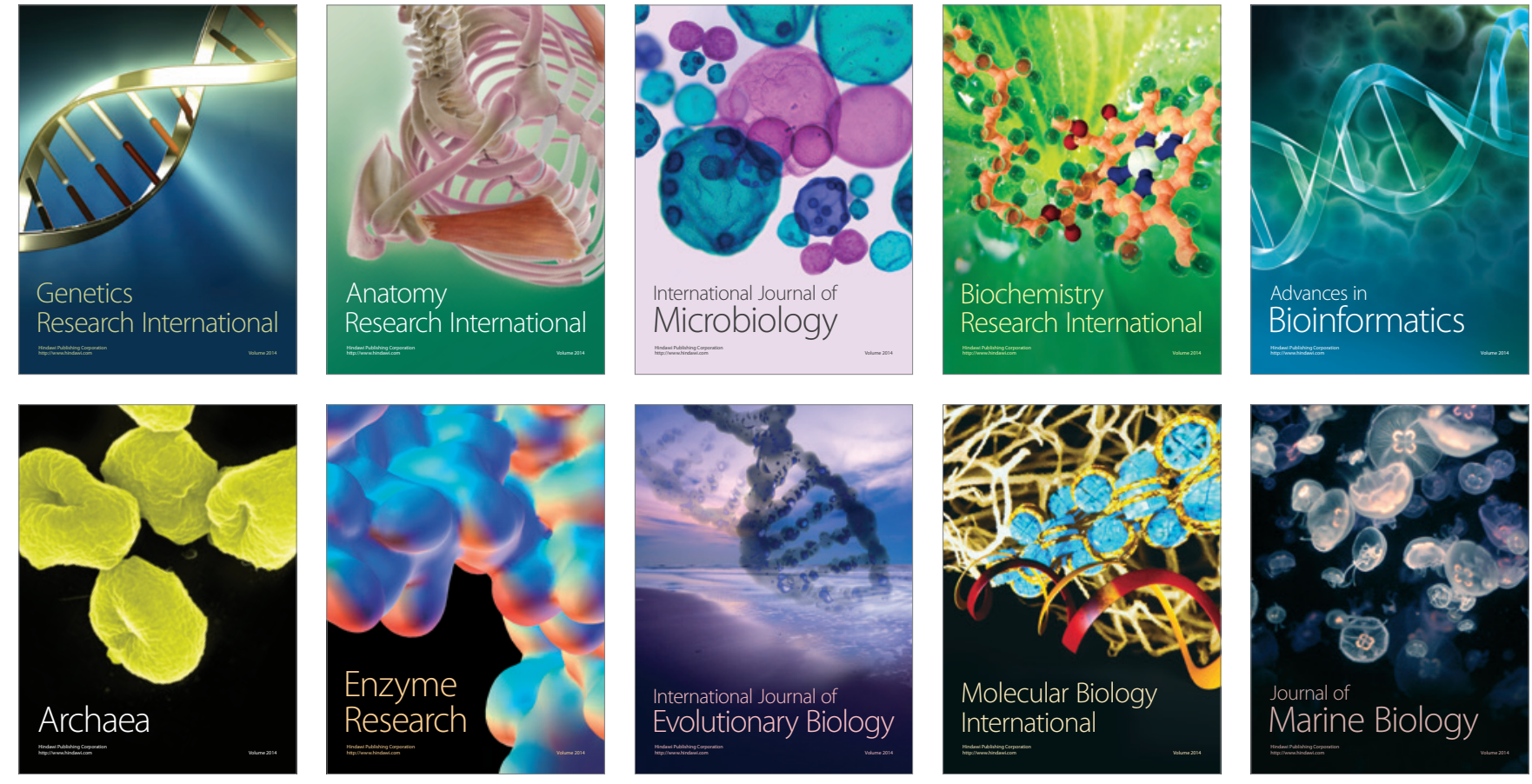